\title{
MEDICAL PHYSICS IN SWEDEN
}

\author{
ARne EngströM, M.D. \\ Karolinska Institutet, Stockholm
}

Biophysics and its medical specialization, medical physics, have undergone an intensive expansion during the last two decades. Scientists from all over the world have discussed the meaning of the concept ' biophysics' for a long time and around 1940 it was mainly contended that biophysics could be defined as the application of physical methods to biological problems. The corresponding definition for medical physics was the application of physical methods to medical problems.

The tremendous development in the physical and technical sciences we have witnessed since I940 has, however, not only given new methods to the biologist or medical research worker, but also given new principles of scientific strategy. Therefore, one is today more inclined to define biophysics and medical physics in operative terms under the heading of ' theoretical biology'. The ultimate goal of this biophysical ideology is to explain the patterns and reactions of living materials in physical and mathematical terms. In this definition the difference between biophysics and medical physics in Sweden is no greater, as both have the same general aim. It would perhaps be safe to state that the development and application of physical techniques for clinical problems is better classified as medical technology or hospital physics.

From the foregoing it is apparent that there does not exist any great difference between biophysics and medical physics: they thus have in relation to physics the same standing as biochemistry and medical biochemistry to pure chemistry.

In the curriculum of the medical schools in Sweden medical physics is taught during the second year of study, i.e. the 'biochemicalphysiological year'. As all medical students have to take this course of medical physics, the teaching aims at giving the students a general understanding of the great present influence of mathematics and physics on biological and medical research. For example, the production and use of radio-isotopes, the problem of the world-wide radioactive fall-out, computers in biology, operations analysis and molecular biology are taught to show the increasing expansion of physics into biology. The subjects are presented in such a way that extensive and complicated formulae are not needed.

Postgraduate teaching, on the other hand, is naturally at an advanced level. In the Swedish medical schools no postgraduate courses in the American sense exist. A medical student acquires after his preclinical subjects the candidate degree, M.K. After his clinical studies, including service as assistant in several clinical subjects, he obtains the licentiate of medicine, M.L., which silows him to get the licence from the Royal Medical Board to practise medicine.

In order to get the degree doctor of medicine, M.D., the M.L. (or with special permission an M.K.) must perform a rather extensive research work and present this as a printed thesis. Often this is published in the form of a supplement to an existing journal and English is the commone language. The research work which eventually? leads to an M.D. is performed in the preclinical or clinical departments. The time spent on a thesis varies from two to ten years.

In the following an account of the research activity in the Department of Medical Physics at Karolinska Institutet, Stockholm, will be given to illustrate some current problems in medical physics and also to indicate that a thorough mathematical and physical training is required besides a medical education for those who will receive an M.D. in a biophysical subject. It should be noted that a inedical school in Sweden can only give the M.D. degree, although in many instances, judging from the content of the thesis, it would be much more appropriate to give a Ph.D.

Several theses issued from the Department of Medical Physics deal with the development and applications of $\mathrm{X}$-ray microscopic techniques. It was early shown ${ }^{3}$ that $\mathrm{X}$-ray microscopy with monochromatic $\mathrm{X}$-rays permitted a quantitative elementary analysis on a cytological level. For example, the amount of calcium and phosphorus could be determined on areas $r o \mu$ in diameter in developing bone and teeth. The method was further refined ${ }^{9}$ to permit also the determination of sulphur in, for example, the various structures 


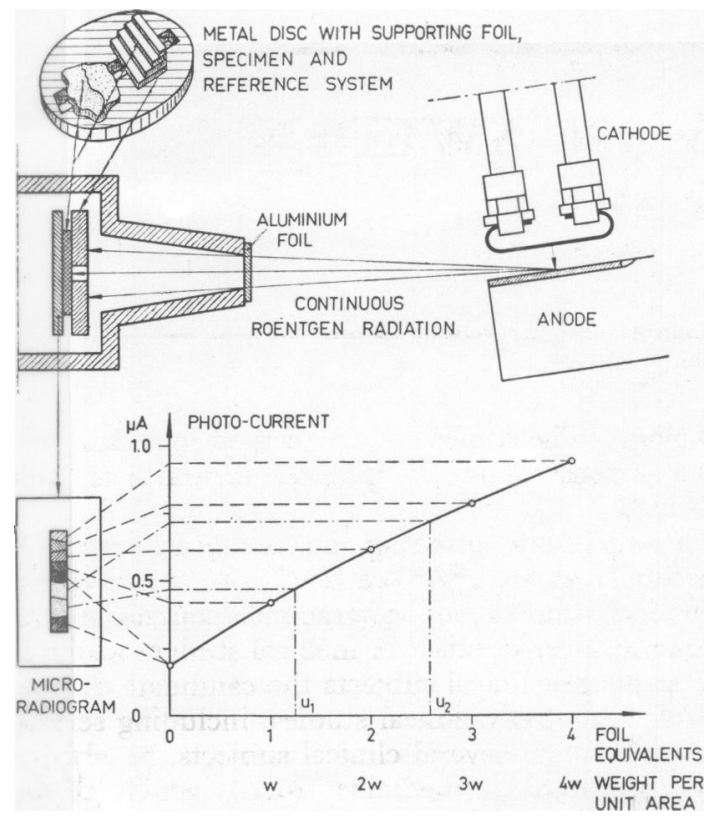

FIG. I.-Schematic representation of the quantitative microradiographic procedure to determine the total dry weight of small biologic objects.

of skin. In general, it can be said that the elementary analysis of microscopic objects by X-ray absorption requires a complicated instrumentation.

The X-ray microscopic methods have been further developed in several directions. The registration of absorption images of soft tissues with $\mathrm{X}$-rays of long wavelength permits under certain conditions the weighing of small cellular structures. ${ }^{4,6,7}$ The procedure is outlined in Fig. I. A tissue section or a smear preparation of cells is placed in contact with an extremely finegrained photographic emulsion and an X-ray absorption image in the scale $I$ to $I$ is produced. This microradiogram, which is recorded simultaneously with the reference system of known characteristics, is then measured in a microdensitometer and from comparison of the data the $\mathrm{X}$-ray transmission through various microscopic cellular structures can be determined. Knowing the wavelengths of the X-rays? the mass - that is, the sum of all the elements in the dehydrated specimen-can be calculated. This weighing method has been used in a great number of investigations concerning the mass and its distribution within the cells and within different cells, for example, in nervous tissues, in glandular tissues, in muscle fibres, in studying the density of the chromosomes during mitosis, etc. ${ }^{4}, 7$

A special case where microradiography or X-ray microscopy has been of very great use is in the investigation of mineralization of bone and other calcified tissues. A microradiogram taken of a thin section of bone and recorded with $\mathrm{X}$-rays with the wavelength $1.54 \AA$ shows the distribution of mineral salts. Fig. 2 shows such a picture and it is evident that various Haversian systems have a varying density, that is, a varying content of mineral salts. This variation can be traced back to the different ages of the osteons, a fact which is closely connected with the continuous rebuilding of bone. Recently the X-ray microscopic method has been further specialized in the case of bone in such a way that microradiograms are recorded with two wavelengths separately, the first one with a maximum absorption that is close to the absorption peak of calcium and the other one with relatively less absorption, that is, just beyond the absorption discontinuity of phosphorus. This dichromatic microradiography permits the simultaneous determination of the amount of mineral salts and also of organic material in the bone specimen. If, as was mentioned earlier, only one microradiogram should be taken, the wavelength must be chosen in such a way that the disturbing influence from the inorganic fraction is as small as possible, and that is why the wavelength I. $54 \AA$ has to be used.

The work on the distribution of mineral salts in bone tissues was supplemented with autoradiographic studies. ${ }^{8}$ From the X-ray microo radiogram it could be predicted that if a radios active isotope was given to the animal such Haversian systems which show the low: degree of ${ }^{+}$ mineralization ought to take up more isotope than those which had a high content of mineral salts. This proves to be the case in the first experiment, which was done by injecting $\mathrm{P}^{32}$-labelled phosphate into an animal. Thus bone-seeking isotopes become unevenly distributed in the skeleton, tending rather to show local concentrations. This problem of the local concentration has in our day a great significance as the radioactive strontium in the fall-out from nuclear weapons tests finally enters the human skeleton. Using such combined studies with microradiography and strontium-9o distribution by radioautography considerable work has been done in order to determine the health hazards from the incorporation of fall-out fission products in the human skeleton. These resultsare summarized in the book 'Bone and Radiostrontium ', by Engström, Björnerstedt, Clemedson and Nelson and published by John Wiley \& Sons in New York. ${ }^{8}$ The studies of health problems in connection with the fall-out have been continued, and recently arguments have been presented to show that when stating figures for the permissible body burden of, for example, strontium-90 mention should be made and consideration taken of whether the isotope is administered 


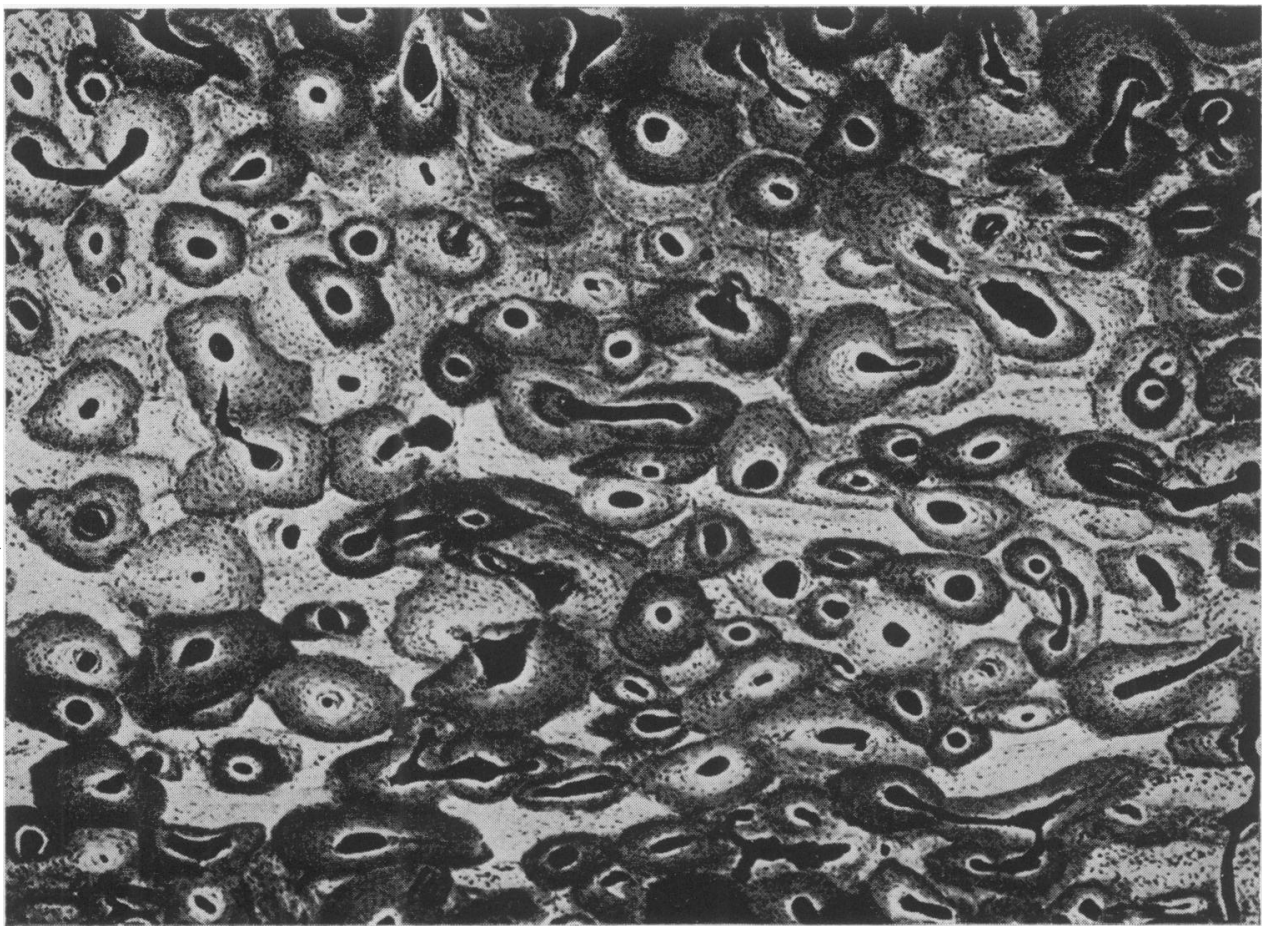

Fig. 2.-Microradiogram of a thinly ground section of bone.

over a long period of time - that is, chronic intakeor given as an 'acute' dose. In this concept 'acute' means short intake time in comparison with the life span of one single osteon and correspondingly ' chronic' administration means long intake time in relation to this life span.

A great deal of the department's activity is focussed on the study of the molecular structure of biological systems and biologically important compounds. Several projects have centered on the problem of the crystallographic structure of the inorganic phase in bone. The precise characteristics of the crystal lattice have been determined and much information has been collected on the problem of the size of the apatite particles. Both narrow-angle $\mathrm{X}$-ray scattering, the measurement of the X-ray diffraction profiles in the wide-angle $\mathrm{X}$-ray diffraction pattern and electron microscopy have been used. Our concept of the size of the apatite particles in bone is best illustrated by the recent findings of Carlström and $\mathrm{Glas}^{2}$ in the department. By measuring carefully the X-ray diffraction profiles they deduce that the elongated apatite particles contained defects or strains. Thus they were able to resolve the $\mathrm{X}$-ray line-broadening effect in the two factors, one due to size and one due to strain; and the present concept is that in bone the ' matured ' crystallites are elongated rods with a width of about $40 \AA$ and a length of somewhat more than $640 \AA$. Similarly, the size of the particles in enamel has been determined and here the width is of the order of $400-500 \AA$ and the length of the order $\mathrm{I}, 000-2,000 \AA$ units. The X-ray crystallographic studies of the mineral phase in bone have been used to obtain information about the possible mechanism for the introduction of ions such as strontium into the mineral phase. Studies on combined calcium-strontium apatites in the wet precipitation have shown that most of the strontium, when incorporated into the skeleton, is fixed by surface absorption and then is further stabilized by epitaxy.

In connection with the behaviour of radioactive isotopes in the organism an extensive theoretical study is being performed, mainly by Bergner. ${ }^{1} \mathrm{He}$ is considering the retention and metabolism of isotopes from an entirely theoretical point of view and is analysing the possibility and the validity of compartment model-building, trying to find out how valid it is and how much information can be obtained from tracer kinetics studies.

Besides the studies on the structure of calcified tissues an extensive work has been performed on the structure and formation of keratin in human epidermis. Swanbeck $\mathbf{1 0}^{\mathbf{1 0}}$ has shown that specimens of the horny layer from normal, ichthyotic and 
psoriatic skin give $\mathrm{X}$-ray diffraction patterns which can be utilized for further studies. The wide-angle diffraction pattern shows that the major components of the horny layer are an $\alpha$-keratin and a fatty acid derivative. It also shows that the preferred orientation of the lipid chains-is perpendicular to the preferred orientation of the protein chains. On the bases of the wide-angle and the narrow-angle diffraction patterns a hypothetical model was proposed for the molecular organization of the fibrillar unit. According to this model, the fibrils consist of a circular protein cylinder surrounded by a lipid layer with the lipid chains standing radially from the protein cylinder. A diffraction pattern of such a system was derived theoretically and it was found by comparison between calculated and experimental diffraction patterns that the protein fibre of the horny layer from normal skin has a diameter of $250 \AA$ and is probably surrounded by a layer of lipids $80 \AA$ thick. This lipid layer was also found in fibrils from ichthyotic and psoriatic scales. The protein fibril of ichthyotic scale has, however, a diameter of $160 \AA$ and the protein fibril of psoriatic scale a diameter of only $70-100 \AA$. Swanbeck has summarized his findings from the $\mathrm{X}$-ray crystallographic studies of skin correlated with the accumulated knowledge of the chemistry and morphology of epidermis in the following way. The keratinization process goes:

I. Synthesis of tonofilaments with a diameter of $100 \AA$ in the lower layers of epidermis.

2. Decomposition of other cellular structures.

3. Aggregation of 5-10 tonofilaments into the $250 \AA$ keratin fibril of the horny layer.

4. Coating of these keratin fibrils with a $80 \AA$ thick lipid layer.

For ichthyosis step number 3 is incomplete and the bundle of 5-10 tonofilaments has probably given rise to two or three fibrils instead of one. For psoriasis step number 3 has completely failed.

The activity at the Department of Medical Physics, Karolinska Institutet, covers a wide range in biophysics. Work goes on, from the construction of new instruments on the one hand (for example, the design for an instrument for $\mathrm{X}$-ray microscopy and the construction of new types of $\mathrm{X}$-ray diffraction cameras, etc.) to theoreticalmathematical studies of phenomena such as the fate of tracers in the organism described in mathematical terms. Along this scale, one end of which is the construction and design of new instruments, and the other end of which is theoretical biology, falls most of the scientific work. To illustrate this point the following list gives the titles of the M.D. theses printed and published which have been issued from the Department of Medical Physics, Karolinska Institutet.
A great number of publications in the general field of biophysics ${ }^{5}$ and medical physics have also been issued in addition to the contributions mentioned in the reference list at the end of this paper. The department publishes annually a list of issued reprints and, if available, such lists and reprints are distributed to those requesting them.

\section{M.D. THESES ISSUED FROM THE DEPARTMENT OF MEDICAL PHYSICS KAROLINSKA ISTITUTET}

Engström, A. 'Quantitative micro- and histochemical elementary analysis by roentgen absorption spectrography ', Acta radiol. (Stockh.), Suppl. 63 (1946).

Bellman, S. 'Microangiography', Acta radiol. (Stockh.), Suppl. 102 (1953).

HedenBerG, I. 'Macroscopic and microscopic changes and stone formation in the urinary tract in experimentally produced vitamin A deficiency in rats and some notes on the effect of large doses of vitamin $A$ on the uterine, vaginal, and vesical epithelium ', Acta chir. scand., Suppl. 192 (1954).

Carlström, D. 'X-ray crystallographic studies on apatites and calcified structures ', Acta radiol. (Stockh.), Suppl. 121 (1955).

LAGERGREN, C. ' Biophysical investigations of urinary calculi. An X-ray crystallographic and microradiographic study ', Acta radiol. (Stockh.), Suppl. I 33 (1956).

WALLGREN, G. 'Biophysical analyses of the formation and structure of human fetal bone. A microradiographic and X-ray crystallographic study', Acta paediat. (Uppsala), Suppl. I 13 (1957).

Holmstrand, K. 'Biophysical investigations of bone transplants and bone implants. An experimental study ', Acta orthop. scand., Suppl. 26 (1957).

OMNELL, K.-A.' Quantitative roentgenologic studies on changes in mineral content of bone in vivo', Acta radiol. (Stockh.), Suppl. I48 (1957).

HAMMARLUND-Essler, E. 'Studies on the mineral component of dental enamel by means of microradiography, autoradiography and X-ray diffraction', Trans. roy. Schools of Dentistry, Stockholm and Umea, No. 5 (1958).

NilsonNe, U. 'Biophysical investigations of the mineral phase in healing fractures ', Acta. orthop. scand., Suppl. 37 (1959).

SwANBECK, G. 'Macromolecular organization of epidermal keratin. An X-ray diffraction study of the horny layer from normal, ichthyotic and psoriatic skin ', Acta derm.-venereol. (Stockh.), Suppl. 43 (1959).

\section{REFERENCES}

1. BERGNER, P. E. (1959): Exp. Cell. Res., 17, 328.

2. CARLSTROM, D., and GLAS, J. E. (1959): Biochim. biophys. Acta, 35, 46.

3. ENGSTRÖM, A. (1946): Acta radiol. (Stockh.), Suppl. 63.

4. ENGSTROM, A. (1959): 'Analytical Cytology', ed. R., Mellors, New York, McGraw Hill Publishing Co.

5. ENGSTROM, A., and FINEAN, J. B. (1957): 'Biological Ultrastructure ', Academic Press. New York.

6. ENGSTRÖM, A., and LINDSTROMM, B. (1950): Biochim. biophys. Acta., 4, 35I,

7. ENGSTROM, A., and LINDSTROM, B. (1958): ' General Cytochemical Methods ', Vol. I, ed. J. F. Danielli, Academic Press, New York.

8. ENGSTROM, A., BÖJRNERSTEDT, R., CLEMEDSON, C. J., and NELSON, A. (1958): 'Bone and Radiostrontium', John Wiley, New York.

9. LINDSTROM, B. (1955): Acta radiol (Stockh), Suppl. 125.

10. SWANBECK, G. (1959): Acta derm.-venereol. (Stockh.) Suppl. 43. 